\title{
Selection for High Yield and Stability among Early Maturing Greengram Genotypes
}

\author{
Emmanuel. K. Mbeyagala ${ }^{1,2}$, R. Amayo ${ }^{1,2}$ \& J. E. P. Obuo ${ }^{1,2}$ \\ ${ }^{1}$ National Semi Arid Reseources Research Institute (NaSARRI), Uganda \\ ${ }^{2}$ National Agricultural Research Organization (NARO), Uganda \\ Correspondence: Emmanuel. K. Mbeyagala, National Semi Arid Resources Research Institute. P.O. Box Private \\ Bag Soroti, Uganda. E-mail: kmbeyagala@gmail.com
}

Received: April 6, 2015 Accepted: May 7, 2015 Online Published: August 15, 2015

doi:10.5539/jas.v7n9p154 URL: http://dx.doi.org/10.5539/jas.v7n9p154

\begin{abstract}
Greengram, Vigna radiata (L.) Wilczek is an important source of proteins and micronutrients to small holder farmers in eastern and northern regions of Uganda. Most of the landraces currently grown by small scale farmers are characterized by low yields and late maturity. In order to identify high yielding and stable varieties, an experiment was conducted to evaluate the yield performance of introduced early maturing genotypes from the World Vegetable Centre (AVDRC) in seven locations of Uganda. Yield performance data for the genotypes was subjected to analysis of variance (ANOVA) to test the significance of genotype $\times$ environmental interactions as well as stability analysis using the yield - stability statistic $\left(\mathrm{YS}_{\mathrm{i}}\right)$ as an aid for simultaneous selection for high yield and stability. Analyses of variance showed that genotype $\times$ environmental interactions $(\mathrm{G} \times \mathrm{E})$ were significant and therefore could not be ignored. Following the detection of significant genotype $\times$ environmental interactions, yield - stability statistics $\left(\mathrm{YS}_{\mathrm{i}}\right)$ were generated and used for simultaneous selection for high yield and stability among the introduced genotypes. Yield-stability statistics $\left(\mathrm{YS}_{\mathrm{i}}\right)$, indicated that three introduced genotypes (Filsan, Sunshine, and Blackgram) in addition to the local check were stable and high yielding. These genotypes need to be assessed for farmer preferences/tastes and other quality traits in on-farm participatory trials before they can be recommended for release.
\end{abstract}

Keywords: yield- stability statistic, Vigna radiata, Vigna mungo, Genotype $\times$ Environmental interaction

\section{Introduction}

Greengram Vigna radiata (L.) Wilczek is one of the important pulse crops widely grown by small holder farmers in the eastern and northern regions of Uganda (Apio Ibedo, 2014). It is a rich source of proteins and micronutrients particularly, iron and zinc with low ant-nutritional factors. Greengram is considered a wonder crop among smallholder farmers due to its ability to tolerate and perform well under drought conditions, short maturity periods and ability to improve soil fertility through nitrogen fixation (Swaminathan et al., 2012). Greengram production in Uganda like much of Sub-Saharan Africa (SSA) still depends largely on late maturing and indeterminate varieties (Shanmugasundaram et al., 2009). However, shifts in rainfall patterns and seasons due to climatic change require the development of varieties that are early maturing. Such new varieties must show high performance for yield and other essential agronomic traits and their superiority should be consistent (stable) over a wide range of environmental conditions (Becker \& Leon, 1988). Yield stability between genotypes is variable due to the wide occurrence of genotype $\times$ environmental interactions $(G \times E)$ i.e. the ranking of genotypes depends on particular environmental conditions where they are grown (Becker \& Leon, 1988). Genotype $\times$ environment $(\mathrm{G} \times \mathrm{E})$ interaction pauses a continuous challenge among plant breeders and agronomists in making cultivar recommendations to farmers because of the associated consequences especially when selection is based on yield alone (Kang, 1993). This is due to lack of emphasis on both yield and stability in most breeding programs (Mekbib, 2002) as well as lack of appropriate policy support for instance the new Ugandan Plant Variety Protection Bill (2010), which governs variety release in the country does not consider yield and stability simultaneously. Kang (1993) warns that cultivar recommendations made by breeders and/ or agronomists on the basis of yield alone as is conventionally done pause a serious risk to growers.

Kang (1993) recently developed a statistic called yield-stability $\left(\mathrm{YS}_{\mathrm{i}}\right)$ that integrates both yield and stability in selecting genotypes tested across a range of environments. Recommendation of high yielding and stable 
Greengram genotypes is particularly important in eastern and northern Uganda due to variations in environmental conditions, production is rain-fed and means of modifying the environment are unavailable. This study therefore aimed at identifying high yielding varieties that have a stable performance across regions using the $\mathrm{YS}_{\mathrm{i}}$ selection criterion.

\section{Materials and Methods}

Twelve early maturing genotypes (11 for Vigna radiata and one for Vigna mungo) were evaluated in seven locations and different seasons. The locations were; Arua (at AbiZARDI), Kaberamaido (at Kaberamaido TVC), Kumi (at Kumi TVC), Moroto (at NabuinZARDI), Lira (at Ngetta ZARDI), Serere (at NaSARRI), and Tororo (at Tororo DATIC) located in eastern, north eastern and north western Uganda from 2013-2014. These locations represent the major Greengram growing areas in Uganda and are characterised by arid and semi arid conditions. All the genotypes except local check (control variety) used in the study were obtained from the World Vegetable Centre (AVDRC) as shown in Table 1. In 2013 first season (2013A), evaluations were conducted only in Serere while in the second season (2013B), genotypes were evaluated in Kumi and Lira. In the first season of 2014 (2014A), genotypes were evaluated in all the sites while in the second season (2014B), genotypes were planted in Arua and Serere. In all locations, genotypes were planted in $2.4 \mathrm{~m} \times 3 \mathrm{~m}$ plots at a spacing of $60 \mathrm{~cm} \times 30 \mathrm{~cm}$ laid out in a Completely Randomised Block Design (RCBD) with each genotype replicated three times. In each season, experimental plots were kept free of weed by hoeing. Fertilizers and/or supplementary water through irrigation were not applied during the trials. Pre-flowering pests especially aphids were controlled by 1-2 sprays (depending on pest pressure) using Dimethoate $40 \% \mathrm{EC}$ at recommended rates. Post flowering pests such as flower thrips (Megalurothrips sjostedti Trybom), pod borers (Maruca vitrata Fabricius) and pod sucking bugs were controlled by 2 sprays using Roket 44 EC (Profenofos 40\% + Cypermethrin 4\%) starting from the budding stage. Pods from each plot were harvested at physiological maturity (i.e when the ripe pods changed colour), dried under the sun for three to four days before threshing and winnowing. The threshed grain was then weighed on a plot basis to obtained plot grain yield which was later extrapolated to yield per hectare. A combined analysis of variance to assess the significance of genotype $\times$ environment interactions was carried out before computing the yield and yield-stability statistics $\left(\mathrm{YS}_{\mathrm{i}}\right)$. Shukla's Stability Variance and Kang's Yield - Stability $\left(\mathrm{Ys}_{\mathrm{i}}\right)$ Statistics were calculated according to (Kang, 1993). All analyses were carried out using R version 3.1.2 (R Core Team, 2014).

Table 1. List of AVDRC Genotypes evaluated in the study

\begin{tabular}{lll}
\hline Cultivar Name & Species & Country of origin \\
\hline Filsan & Vigna radiata & Taiwan \\
Blackgram & Vigna mungo & Thailand \\
Mauritius 1 & Vigna radiata & Mauritius \\
VC614850-12 & Vigna radiata & Thailand \\
VC6173B10 & Vigna radiata & Thailand \\
Yellow mungo & Vigna radiata & Philippines \\
KPS 1 & Vigna radiata & Taiwan \\
VC6137B14 & Vigna radiata & Thailand \\
VC63724560 & Vigna radiata & Thailand \\
VC6153B20P & Vigna radiata & Thailand \\
Sunshine & Vigna radiata & Unknown \\
Local check & Vigna radiata & Uganda \\
\hline
\end{tabular}

Note. AVDRC $=$ World Vegetable Center.

\section{Results}

Analysis of variance (Table 2$)$ showed that genotype $\times$ environmental interactions were significant $(p<0.001)$, therefore it was inappropriate to select genotypes on the basis of yield alone. The effect of genotype was also significant (at $\mathrm{p}=0.001$ ) though the interaction and environmental effects were more significant $($ at $\mathrm{p}<0.001)$. There were differences in mean performance of genotypes at the different locations (Table 3 ). 
Table 2. Analysis of variance for genotype $\times$ environmental interaction effects

\begin{tabular}{llll}
\hline Source of variation & DF & Mean square & P value \\
\hline Genotypes & 11 & 72814.4 & 0.001 \\
Environments & 11 & 1145137 & $<0.001$ \\
Interactions & 121 & 23018.4 & $<0.001$ \\
Heterogeneity & 11 & 0.58 & 0.838 \\
Residual & 110 & 11960.5 & $<0.001$ \\
Pooled error & 264 & &
\end{tabular}

Note. $\mathrm{DF}=$ degrees of freedom.

Table 3. Average Yield $\left(\mathrm{Kgha}^{-1}\right)$ of all the genotypes evaluated at the different locations

\begin{tabular}{|c|c|c|c|c|c|c|c|c|c|c|c|c|}
\hline Parameter & Arua & & Kaberamaido & Kumi & & Moroto & Lira & & Serere & & & Tororo \\
\hline Season/year & $2014 \mathrm{~A}$ & 2014B & $2014 \mathrm{~A}$ & 2013B & $2014 \mathrm{~A}$ & $2014 \mathrm{~A}$ & 2013B & $2014 \mathrm{~A}$ & $2013 \mathrm{~A}$ & $2014 \mathrm{~A}$ & 2014B & $2014 \mathrm{~A}$ \\
\hline Mean yield & 338.8 & 209.1 & 536.3 & 474.5 & 763.2 & 360.7 & 173.3 & 538.2 & 258.9 & 431.9 & 392.7 & 431.5 \\
\hline $\mathrm{SE}$ & 22.4 & 24.2 & 13.3 & 26.1 & 17.2 & 8.2 & 15.6 & 40.2 & 25.4 & 25.9 & 25.6 & 15.2 \\
\hline
\end{tabular}

Note. $\mathrm{SE}=$ standard error.

Following the detection of significant genotype $\times$ environmental interactions, $\mathrm{YS}_{\mathrm{i}}$ statistics for the twelve genotypes were calculated as listed below as described by Kang (1993) to give results in Table 4.

1) Determine the contribution of each genotype to Genotype $\times$ Environmental interaction by calculating $\sigma_{i}^{2}$ (Shulka, 1972) as follows:

$$
\sigma_{i}^{2}=[1 /(s-1)(t-1)(t-2)] \times\left[t(t-1) \sum_{j}\left(\mu_{i j}-\overline{\mu_{i}}\right)^{2}-\sum_{i} \sum_{j}\left(\mu_{i j}-\bar{\mu}_{i}\right)^{2}\right]
$$

Where, $\mu_{i j}=X_{i j}-\overline{X_{j}}, X_{i j}=$ observed yield value of the ith genotype in jth environment, $\overline{X_{j}}=$ mean of all genotypes in jth environment, $\bar{\mu}_{i}=\sum_{j} \mu_{i j} / s, s=$ number of environments and $\mathrm{t}=$ number of genotypes. Shukla's Stability Variance, $\sigma_{i}^{2}$ and Kang's Yield - Stability $\left(\mathrm{YS}_{\mathrm{i}}\right)$ statistics were computed using Agricolae package in R (Felipe de Mendiburu, 2014).

2) Arrange genotypes from highest to lowest yield and assign yield rank $\left(Y^{\prime}\right)$, with the lowest yielding genotype receiving the rank of 1 .

3) Calculate protected $\operatorname{LSD}_{\alpha(2)}$ for mean yield comparisons [ $\alpha(2)$ refers to a two-tailed test] as $\mathrm{t}_{\alpha(2)}, v(2 \mathrm{EMS} / \mathrm{s} \times$ $\mathrm{r}^{1 / 2}$ ), where EMS = error mean square, $\mathrm{v}=\mathrm{df}$ associated with EMS, and $\mathrm{r}=$ number of replications.

4) Adjust $Y$ ' according to LSD, and determine adjusted yield rank (Y) [as shown in Table 4].

5) Assign respective stability-variance statistic ( $\sigma_{i}^{2}$ values to genotypes and determine whether or not $\sigma_{i}^{2}$ is significant at $\alpha(2)=0.10,0.05,0.01$, using an approximate test with (s - 1), $\mathrm{v}$ df [a significant $\sigma_{i}^{2}$ indicates that genotype performance across environments was unstable].

6) Assign stability rating (S) as follows: $-8,-4$, and -2 for $\sigma_{i}^{2}$ significant at $\alpha=0.01,0.05$, and 0.1 , respectively; and 0 for non significant $\sigma_{i}^{2}$ [The stability ratings of $-8,-4$, and -2 were chosen because they changed genotype ranks from those based on yield alone (Y') (Kang, 1993).

7) Sum adjusted yield rank (Y) and stability rating (S) for each genotype to determine $\mathrm{YS}_{\mathrm{i}}$ statistic.

8) Calculate mean $Y S_{i}$ as $\Sigma Y S_{i} /$ t. Select genotypes with $Y S_{i}>$ the mean $Y S_{i}$. 
Table 4. Yield-stability statistic $\left(\mathrm{YS}_{\mathrm{i}}\right)$ for simultaneous selection for yield and stability in Greengram trials

\begin{tabular}{lllllllc}
\hline Genotype & Mean Yield & Yield Rank (Y) & Adjustment to rank* & Adjusted Y & Stability variance & Stability rating (S) & YS $^{\text {i }}$ \\
\hline Filsan & 463 & 12 & 3 & 15 & $54522.4^{* *}$ & -8 & $7+$ \\
Blackgram & 454.6 & 11 & 3 & 14 & $53573.6^{* *}$ & -8 & $6+$ \\
Sunshine & 428.8 & 10 & 3 & 13 & $22254.3^{* *}$ & -8 & $5+$ \\
Local check & 417.8 & 9 & 3 & 12 & $24233.3^{* *}$ & -8 & $4+$ \\
VC61485012 & 382 & 8 & -3 & 5 & $28630.2^{* *}$ & -8 & -3 \\
Mauritius1 & 375.5 & 7 & -3 & 4 & $16726.2^{* *}$ & -8 & -4 \\
VC6173B10 & 372.3 & 6 & -3 & 3 & $13740.3^{* *}$ & -8 & -5 \\
Yellowmungo & 369 & 5 & -3 & 2 & $26554.7^{* *}$ & -8 & -6 \\
KPS1 & 344.4 & 4 & -3 & 1 & $11756.6^{* *}$ & -8 & -7 \\
VC6137B14 & 342 & 3 & -3 & 0 & $10034.5^{* *}$ & -8 & -8 \\
VC63724560 & 339.9 & 2 & -3 & -1 & $6162.5^{* *}$ & -8 & -9 \\
VC6153B20P & 337.1 & 1 & -3 & -2 & $8032.8^{* *}$ & -8 & -10 \\
Mean & $\mathbf{3 8 5 . 5}$ & & & & & & -2.5 \\
LSD (0.05) & $\mathbf{0 . 5 5}$ & & & & &
\end{tabular}

Note. $\mathrm{YS}_{\mathrm{i}}=$ yield-stability statistic; + Genotypes selected on the basis of $\mathrm{YS}_{\mathrm{i}}$.

* Adjustment for +1 for mean yield $>$ overall mean yield (OMY); +2 for mean yield $\geq 1 \mathrm{LSD}$ above OMY; +3 for mean yield $\geq 2$ LSD above OMY; -1 for mean yield $<$ OMY; -2 for mean yield $\leq 1$ LSD below OMY; and -3 for mean yield $\leq 2 \mathrm{LSD}$ below OMY.

$* * \sigma_{i}^{2}$ Significant at $\alpha=0.01$

Three introduced genotypes (Blackgram, Filsan, and Sunshine) in addition to the local check had yield-stability statistic $\left(\mathrm{YS}_{\mathrm{i}}\right)$ values greater than the mean $\mathrm{YS}_{\mathrm{i}}$ value $(-2.5)$ (Table 4). These genotypes gave high mean yield values with low genotype $\times$ environment interaction (an indicator of wide adaptability) and are therefore preferred since they can express high yield potential in varied environments. Therefore these genotypes are both stable and high yielding and are suitable for cultivation in the Ugandan environments in which they were tested. These genotypes will be subjected to farmer preference assessment and other quality parameters in on-farm participatory trials before they can be submitted for release and subsequent production.

\section{Discussion}

The presence of Genotype $\times$ Environmental interactions pause a challenge to plant breeders because it implies that the behaviour of the genotypes in the trial depends upon the particular environment in which they are grown (Ceccarelli, 1989; Hill, 1975). Thus the performance of any one of the genotypes relative to the remaining genotypes grown in the same environment will be inconsistent, such inconsistencies resulting either in alteration to the ordering of the genotypes from one environment to the next, or to changes in the absolute differences between genotypes which leave the rank order unchanged. Such interactions make utilizing data from multi-environmental trials complex (Tukamuhabwa et al., 2012). When there are Genotype $\times$ Environmental interactions, they can be dealt with through; 1) ignoring them (by using genotypic means across environments); 2) avoid them (by grouping similar environments together) or 3) exploit them in breeding objectives by analyzing and interpreting genotypic and environmental differences (Eisemann et al., 1990). The first approach pauses a great risk to growers (Kang, 1993) while with the second approach, useful information about environments may be lost especially if broad adaptation were the goal (Kang, 1997). Third approach enables researchers to identify the causes of genotype $\times$ environmental interactions and provides opportunities to address them through genetic or environmental manipulations to enhance productivity. In order to conserve resources, genotypes that are widely adaptable and with reliable performance across environments need to be identified through analysis and utilization of genotype $\times$ environmental interactions. In order to analyze genotype $\times$ environmental interactions, it is important to integrate both yield and stability of genotype performances across environments using reliable stability statistics (Kang, 1993). A yield-stability statistic $\left(\mathrm{YS}_{\mathrm{i}}\right)$ that uses Genotype $\times$ Environmental interaction with great emphasis on stability component has been recommended in identifying high yielding and stable 
genotypes (Kang, 1993). In this study, $\mathrm{YS}_{\mathrm{i}}$ was used in studying the performance of introduced Greengram and Blackgram genotypes in different growing areas in Uganda. The results in this study showed that genotype $\times$ environmental interactions were significant, therefore it was inappropriate to select genotypes on the basis of mean yield alone as is conventionally done (Kang, 1993) but instead both genotype yield and stability of performance were needed to evaluate genotype performance. Kang (1993) highlighted the fact that researchers who emphasize stability of performance than currently done in the selection process would benefit farmers. Farmers would have a greater risk of suffering yield losses when a variety is chosen only on the basis of mean yield alone than when selection is based on yield and stable performance. It is a fact that farmers would prefer to use a high-yielding cultivar that exhibits temporal adaptation and might be willing to sacrifice some yield if they are guaranteed, to some extent, that a cultivar would produce consistently from year to year (Kang et al., 1991). Breeding for stability of performance under variable conditions is a complex and difficult task because selection pressure is variable and unpredictable. Therefore, evaluation of varieties under different environments and adoption of simultaneous selection for yield and stability is a reliable selection criterion that has to be used in any plant breeding programme (Mekbib, 2002). The finding that the local check commonly grown by farmers gave a stable yield performance across the test environments is not surprising since farmers especially in marginal areas always grow landraces that are suitable to their environments as well as those that meet their needs and preferences (Vernooy, 2003). The mean yield values for the genotypes evaluated in this study are still below those required for an ideal variety (> 2 tons/ha) (Shanmugasundaram et al., 2009) and therefore more needs more research is needed in breeding as well as crop agronomy in order to raise yield so as to enhance returns to farmers.

In addition to the stable performance of the three genotypes identified in this study, other traits need to be considered as these may be useful to farmers through on-farm participatory trials. This is because it enables researchers to take advantage of farmers' knowledge and experience thus allowing a quick identification of promising genotypes and eventually contributing to the improvement of a breeding program (Abidin et al., 2005).

\section{Conclusion}

High Genotype $\times$ Environmental interaction complicates breeding work because it makes it difficult to predict how genotypes selected under a given set of conditions will perform in a different set of conditions. By exposing a number of genotypes to a set of contrasting environments it is possible to identify genotypes with a high average yield and low $\mathrm{G} \times \mathrm{E}$ interaction. Such genotypes are commonly referred to as widely adapted genotypes and they possess characteristics, such as resistance to pests and tolerance to environmental stress factors that enhance their performance. With the help of YSi, it was possible to identify three genotypes (Blackgram, Filsan and Sunshine) that are both high yielding and stable among the introduced genotypes that would be beneficial to farmers if they are released for production.

\section{Acknowledgements}

The authors are grateful to the World Bank and the Government of Uganda for providing funds that were used to conduct this work under the ATAAS project. We also thank National Semi Arid Reseources Research Institute (NaSARRI) and National Agricultural Research Organization (NARO) for providing facilities that enabled us to carry out the work presented in this paper. The contributions of Omadi Bob, Okwang Dodah and the entire staff of Dryland Legume Research Programme at NaSARRI in the management of trials are duly acknowledged.

\section{References}

Abidin, P. E., Eeuwijk, F. van, Stam, P., Struik, P. C., Malosetti, M., Mwanga, R. O., \& Carey, E. E. (2005). Adaptation and stability analysis of sweet potato varieties for low-input systems in Uganda. Plant Breeding, 124(5), 491-497. http://dx.doi.org/10.1111/j.1439-0523.2005.01149.x

Apio Ibedo, S. (2014). Analysis of the Greengram value chain in Uganda (Thesis). Makerere University. Retrieved from http://dspace.mak.ac.ug/handle/10570/3242

Becker, H. C., \& Leon, J. (1988). Stability analysis in plant breeding. Plant Breeding, 101(1), 1-23. http://dx.doi.org/10.1111/j.1439-0523.1988.tb00261.x

Ceccarelli, S. (1989). Wide adaptation: How wide? Euphytica, 40(3), 197-205.

Eisemann, R. L., Cooper, M., \& Woodruff, D. R. (1990). Beyond the analytical methodology, better interpretation and exploitation of GE interaction in plant breeding. In M. S. Kang (Ed.), Genotype-by-environment interaction and plant breeding (pp. 108-117). Louisiana State Univ. Agric. Center, Baton Rouge, LA. 
Felipe, de M. (2014). Agricolae: Statistical Procedures for Agricultural Research (R Package Version 1, pp. 1-8). Retrieved from http://CRAN.R-project.org/package=agricolae

Hill, J. (1975). Genotype-environment interactions - A challenge for plant breeding. J. Agric. Sci., 85, $477-493$. http://dx.doi.org/10.1017/S0021859600062365

Kang, M. S. (1993). Simultaneous selection for yield and stability in crop performance trials: Consequences for $\begin{array}{llll}\text { growers. } & \text { Agronomy } & \text { Journal, } & \text { 754-757), }\end{array}$ http://dx.doi.org/10.2134/agronj1993.00021962008500030042x

Kang, M. S. (1997). Using Genotype by Environment Interaction for Crop Cultivar. Advances in Agronomy, 62, 199. http://dx.doi.org/10.1016/S0065-2113(08)60569-6

Kang, M. S., Gorman. D. P., \& Pham, H. N. (1991). Application of a stability statistic to international maize yield trials. Theor: Appl. Genet., 81, 162-165. http://dx.doi.org/10.1007/BF00215718

Mekbib, F. (2002). Simultaneous selection for high yield and stability in common bean (Phaseolus vulgaris) genotypes. The Journal of Agricultural Science, 138(03), 249-253. http://dx.doi.org/10.1017/S0021859602001946

Plant Variety Protection Bill. (2010). Bill No. 2 (p.37). Ministry of Agriculture, Animal Industry and Fisheries (MAAIF).

R Core Team. (2014). R: A language and environment for statistical computing. R Foundation for Statistical Computing, Vienna, Austria. Retrieved from http://www.R-project.org

Shanmugasundaram, S., Keatinge, J. D., \& Hughes, d'Arros J. (2009). The mungbean transformation: Diversifying crops, defeating malnutrition. IFPRI, 00922.

Shukla, G. K. (1972). Some statistical aspects of partitioning genotype-environmental components of variability. Heredity, 29, 237-245. http://dx.doi.org/10.1038/hdy.1972.87

Swaminathan, R., Singh, K., \& Nepalia, V. (2012). Insect Pests of Greengram Vigna radiata (L.) Wilczek and Their Management. In G. Aflakpui (Ed.), Agricultural Science (p. 252). InTech. http://dx.doi.org/10.5772/35176

Tukamuhabwa, P., Oloka, H. K., Sengooba, T., \& Kabayi, P. (2012). Yield stability of rust-resistant soybean lines at four mid-altitude tropical locations. Euphytica, 183, 1-10. http://dx.doi.org/10.1007/s10681-011-0404-3

Vernooy, R. (2003). In focus: Seeds that give participatory plant breeding. International Development Research Centre, Ottawa, Canada.

\section{Copyrights}

Copyright for this article is retained by the author(s), with first publication rights granted to the journal.

This is an open-access article distributed under the terms and conditions of the Creative Commons Attribution license (http://creativecommons.org/licenses/by/3.0/). 